\title{
PUBLISITAS
}

Journal of Social Sciences and Politics

Vol. 7 No. 2 April 2020

p-ISSN : 2252-4150

e-ISSN : 2716-3474

Tersedia online di http://ejurnal.stisipolcandradimuka.ac.id/index.php/JurnalPublisitas/

\section{Pengaruh Organizational Citizenship Behavior Terhadap Kinerja Pegawai Di Kantor Kecamatan Banjarmasin Utara}

\author{
Fadly $^{1}$, Muhammad Anshori ${ }^{2}$, Dhena Aldhalia ${ }^{3}$ \\ ${ }^{1}$ Ilmu Pemerintahan, Fakultas Ilmu Sosial dan Ilmu Politik, Universitas Lambung Mangkurat-Jl. Brigjen \\ H. Hasan Basri, Banjarmasin. 70123 \\ ${ }^{2}$ Ilmu Pemerintahan, Fakultas Ilmu Sosial dan Ilmu Politik, Universitas Lambung Mangkurat- Jl. Brigjen \\ H. Hasan Basri, Banjarmasin. 70123 \\ ${ }^{3}$ Ilmu Pemerintahan, Fakultas Ilmu Sosial dan Ilmu Politik, Universitas Lambung Mangkurat- Jl. Brigjen \\ H. Hasan Basri, Banjarmasin. 70123 \\ E-mail:fadly@ulm.ac.id
}

\begin{abstract}
ABSTRAK
Kajian ini bertujuan menggali terkait pengaruh Organizational Citizenship Behavior (OCB) terhadap kinerja pegawai di Kantor Kecamatan Banjarmasin Utara. Diharapkan kajian ini berguna bagi organisasi pemerintah berupa suatu data terkait oleh pengaruh Organizational Citizenship Behavior (OCB) berkenaan dengan kinerja pegawai di Kantor Kecamatan Banjarmasin Utara. Studi ini adalah penelitian asosiatif dengan metode kuantitatif. Pengambilan data dilakukan dengan menggunakan metode survei lapangan serta membagikan kuesioner kepada seluruh pegawai Kantor Kecamatan Banjarmasin Utara. Acuan teori dari Organ dalam Djati mengenai faktor-faktor yang mempengaruhi Organizational Citizenship Behavior (OCB). Hasil analisis data dalam penelitian ini menggunakan uji validitas dan reliabilitas dengan program SPSS versi 22 adalah valid dan reliabel. Informasinya menganalisis dengan memakai analisis regresi simple, uji koefisien determinasinya serta uji t. Dapat disimpulkan bahwa ada pengaruh Organizational Citizenship Behavior (OCB) terhadap kinerja dari pegawai di Kantor Kecamatan Banjarmasin Utara. Hal ini dapat dibuktikan dengan signifikansi a $=0.05$ yang mana hasil uji $\mathrm{t}=6,203$ dan signifikansinya $<0,05(0,000<0,05)$ artinya hipotesis dapat dikatakan bahwa Ho ditolak dan Ha diterima. Jadi, kesimpulan yang didapatkan bahwa Organizational Citizenship Behavior (OCB) memberikan pengaruh yang signifikan terhadap kinerja pegawai Di Kantor Kecamatan Banjarmasin Utara. Saran dari kajian ini diharapkan mampu menciptakan budaya perilaku dan keadaan akan Organizational Citizenship Behavior (OCB) pegawai agar dapat meningkatkan produktivitas sumber daya manusia dalam meningkatkan produktivitas.
\end{abstract}

Kata kunci : Organizational citizenship behavior (OCB), Kinerja, Kepegawaian

\section{ABSTRACT}

This study aims to explore the influence of Organizational Citizenship Behavior (OCB) on employee performance in the North Banjarmasin District Office. It is hoped that this study will be useful for government organizations in the form of data related to the influence of Organizational Citizenship Behavior (OCB) with respect to employee performance in the North Banjarmasin District Office. This study is an associative research with quantitative methods. Data was collected using field survey methods and distributed questionnaires to all employees of the North Banjarmasin District Office. Theory references from the internal organs regarding 
the factors that influence Organizational Citizenship Behavior (OCB). The results of data analysis in this study using validity and reliability tests with the SPSS version 22 program are valid and reliable. The information is analyzed using simple regression analysis, the coefficient of determination test and the $t$ test. It can be concluded that there is an influence of Organizational Citizenship Behavior (OCB) on the performance of employees in the North Banjarmasin District Office. This can be evidenced by the significance of a $=0.05$ which where the test results and their significance $t=6.203<0.05(0.000<0.05)$ means that the hypothesis can be said that Ho rejected and Ha accepted. So, the conclusion is that the Organizational Citizenship Behavior (OCB) has a significant effect on employee performance in the North Banjarmasin District Office. Suggestions from this study are expected to be able to create a culture of behavior and conditions Organizational Citizenship Behavior for employee(OCB) in order to increase the productivity of human resources in increasing productivity.

Keywords: Organizational Citizenship Behavior (OCB), Performance, Staffing

\section{PENDAHULUAN}

Dalam suatu organisasi sumber daya manusia adalah sebagai tolak ukur dalam keberhasilan suatu organisasi. Sekarang ini banyak tantangan yang harus dialami organisasi seperti bagaimana organisasi menghadapi perubahan dari eksternal dan beradaptasi dengan perubahan yang ada dalam internal organisasi.

\section{Organizational Citizenship} Behavior (OCB) diharapkan dapat memberi sumbangsih bagi organisasi seperti meningkatnya produktivitas rekan kerja, peningkatan produktivitas dari manajer, menghemat sumber daya yang dimiliki manajemen dan organisasi keseluruhan. Kecamatan Banjarmasin Utara merupakan bagian dari Kota Banjarmasin. Kantor Kecamatan Banjarmasin Utara adalah salah satu kantor pemerintahan yang memiliki layanan kepada masyarakat.

Mengenai masalah pelayanan, maka kinerja dari para pegawai Kantor Kecamatan Banjarmasin Utara bergantung pada pengaruh faktor internal dan eksternal, sedangkan Organizational Citizenship Behavior (OCB) merupakan perilaku yang berasal dari dalam diri pegawai yang berpengaruh atas lingkungan internal kantornya. Oleh sebab itu kinerja yang dihasilkan akan sangat berpengaruh terhadap sistem kerja kantor.

Dari hasil pengamatan inilah peneliti tertarik dan memberikan acuan untuk meneliti bagaimana variabel Organizational Citizenship Behavior (OCB) berpengaruh pada kinerja pegawai di Kantor Kecamatan Banjarmasin Utara Kota Banjarmasin Provinsi Kalimantan Selatan.

Berangkat dari uraian latar belakang, peneliti ingin menganalisis apakah Organizational Citizenship Behavior (OCB) berpengaruh positif terhadap kinerja pegawai di kantor Kecamatan Banjarmasin Utara serta seberapa besar pengaruh dari Organizational Citizenship Behavior (OCB) terhadap kinerja pegawai di kantor Kecamatan Banjarmasin Utara.

\section{TINJAUAN PUSTAKA}

Organizational Citizenship Behavior (OCB) 
Organizational Citizenship

Behavior (OCB) merupakan unsur dari pada ilmu sikap, OCB adalah sikap yang tidak dilihat dan tidak diperhitungkan. OCB adalah perilaku yang pada dasarnya tidak diatur secara resmi (perilaku bebas) yang dapat meningkatkan produktivitas dari pegawai.

\section{A. Definisi Organizational Citizenship Behavior (OCB)}

Makna dari Organizational Citizenship Behavior (OCB) lebih mengarah kepada sikap dari para individu dalam menunaikan tugasnya lebih dari apa yang seharusnya dikejakan.

Oleh karena itu penulis mengambil kesimpulan bahwa OCB merupakan sebuah sikap dari pegawai organisasi yang tidak diatur secara resmi, akan tetapi dapat memberikan peningkatan terhadap kinerja pegawai.

B. Dimensi

Organizational Citizenship Behavior (OCB)

Terdapat pendapat-pendapat para ahli berkaitan perilaku OCB dari para pegawai. Organ dalam buku Djati (2009:22) menerangkan ada lima dimensi di dalam OCB, yaitu:

Altruisme,

Conscientiousness, Sportsmanship, Courtesy, dan Civic Virtue.

\section{Indikator Organizational Citizenship Behavior (OCB)}

Peneliti menggunakan teori tentang OCB dari Dennis W. Organ dalam Djati (2009:22), yaitu sebagai berikut: altruism yaitu ketidakegoisan, conscientiousness yaitu sifat berhati-hati, sportsmanship yaitu sikap sportif, courtesy yaitu kesopanan, dan civic virtue yaitu moral kemasyarakatan. Dengan alasan penggunaan teori ini karena teorinya yang relevan dengan penelitian sejenis terkait Organizational Citizenship Behavior (OCB).

\section{Kinerja Organisasi}

Setiap pemberi kerja dan para pekerja selalu menginginkan peningkatan kinerja. Dalam lain hal, para pegawainya harus kompeten agar meningkatkan produktivitas dan promosi kerja.

\section{A. Definisi Kinerja Organisasi}

Kinerja merupakan suatu unsur yang tidak dapat dipisah dari lembaga organisasi, yang mana baik itu lembaga pemerintahan maupun Lembaga swasta. Kinerja pada dasarnya merupakan prestasi kerja atau tingkat keberhasilan seseorang dalam mengerjakan tugasnya.

B. Pengukuran Kinerja Organisasi

Menurut BPKP (Badan

Pengawasan Keuangan dan Pembangunan) pada buku Mahsun (2006: 33) skala dari pengukuran kinerja meliputi beberapa item, yaitu sebagai berikut:

1) Kebijakan;

2) Perencanaan dan penganggaran;

3) Kualitas;

4) Keadilan;

5) Pertanggungjawaban.

\section{Indikator Kinerja Organisasi}

Dari berbagai pendapat tentang masalah pengukuran kinerja, pengukuran yang tepat dalam mengukur kinerja organisasi di sektor publik khususnya kantor Kecamatan Banjarmasin Utara ialah teori dari BPKP yang diambil dari buku Pengukuran Kinerja Sektor Publik oleh Mohammad Mahsun, yaitu kebijakan, perencanaan serta penganggaran, kualitas, kehematan, keadilan, dan 
pertanggungjawaban dari setiap indikator yang harus berhubungan satu sama lain.

Hubungan antara Organizational Citizenship Behavior (OCB) dengan Kinerja Organisasi

Ada hubungan antara Organizational Citizenship Behavior (OCB) dengan tingkat kinerja organisasi yang bisa dilihat di dalam jurnal-jurnal berikut. Penulis Marita Ahdiyana dengan jurnalnya yang berjudul "Dimensi Organizational Citizenship Behavior (OCB) di dalam Kinerja Organisasi" ditemukan bahwa OCB memiliki cukup pengaruh yang signifikan dalam keberhasilan mencapai suatu tujuan dalam organisasi.

\section{METODE PENELITIAN}

\section{Jenis Penelitian}

Jenis penelitian yang digunakan dalam kajian ini adalah penelitian asosiatif dengan metode kuantitatif.

\section{Lokasi Penelitian}

Lokasi penelitian ini dilakukan di Kantor Kecamatan Banjarmasin Utara, Kota Banjarmasin, Provinsi Kalimantan Selatan.

\section{Populasi dan Sampel}

Pada penelitian ini jumlah pegawai Kantor Kecamatan Banjarmasin Utara adalah 25 orang. Dikarenakan populasi kurang dari 100 maka keseluruhan dijadikan sebagai sampel.

\section{Jenis dan Sumber Data}

\section{A. Jenis Data}

Jenis data dalam penelitian ini adalah menggunakan data kuantitatif hasil dari kuesioner.

\section{B. Sumber Data}

Sumber datanya ialah sebagai berikut.

1) Data Primer

Data primer penelitian ini diperoleh dengan membagi kuesioner kepada semua sampel.

2) Data Sekunder

Data sekunder penelitian ini adalah literatur dan dokumentasi.

\section{Metode Pengumpulan Data}

Metode yang digunakan yaitu berupa survei lapangan serta membagikan kuesioner kepada seluruh pegawai Kantor Kecamatan Banjarmasin Utara.

\section{Identifikasi Variabel}
A. Variabel X: Organizational Citizenship Behavior (OCB).

B. Variabel Y: Kinerja Organisasi.

\section{Operasional Variabel}

Operasional variabel merupakan faktor atau variabel yang digunakan dalam penelitian untuk mempermudah serta memberikan pemahaman terhadap pembahasan penelitian ini.

\section{Skala Pengukuran Variabel}

Skala yang dipakai dalam mengukur variabel bebas dan variabel terikat dalam penelitian ini adalah Skala Likert.

\section{Teknik Analisis Data}

Teknik analisis data yang digunakan ialah analisis Regresi Linear Sederhana, Uji Parsial dan Uji Determinasi memakai SPSS 22.

\section{HASIL PENELITIAN}

\section{Analisis Regresi linear Sederhana}

Secara matematis jenis fungsi dari regresi linear sederhananya dirumuskan:

$$
\mathrm{Y}=15,978+1,022 . \mathrm{X}
$$


A. Nilai konstantanya sebesar 15, 978 menunjukan hasil bahwa apabila faktor Organizational Citizenship Behavior (OCB) (X) tidak berubah, maka kinerja organisasinya (Y) adalah sebesar 15,978 .

B. Nilai dari koefisien sebesar 1,022 dalam faktor Organizational Citizenship Behavior (OCB) (X) menunjukan hasil terdapat pengaruh searah yang mana meningkatnya pada faktor Organizational Citizenship Behavior (OCB) (X) dampaknya kepada peningkatan Kinerja Organisasi (Y) sebesar 100,2\%.

\section{Uji Parsial t}

Jika nilai t-nya mempunyai nilai probabilitas masing-masing, faktornya lebih kecil dari tingkat alpha

$$
(\alpha)=0,05
$$

maka dinyatakan bahwa variabel bebasnya berpengaruh terhadap Kinerja Organisasi (Y). Adapun nilai t tabelnya sebesar 2,069 (Terlampir di tabel distribusi t).

Pengaruh yang telah dihasilkan oleh variabel bebas terhadap variabel terikat adalah Organizational Citizenship Behavior (OCB) (X), mempunyai nilainya terhitung sebesar 6,203 dan nilai signifikansinya sebesar 0,000. Itu merupakan hasil dari Organizational Citizenship Behavior (OCB) (X) punya pengaruh signifikan terhadap Kinerja Organisasi (Y). Hasil dari pernyataannya adalah thitung lebih besar dari nilai ttabel $(6,203>2,069)$ dan nilai signifikannya lebih rendah dari nilai signifikan $(0,000<$ 0 , 05). Jadi, dapat disimpulkan hipotesisnya adalah dasar penelitian (Ho) yang menyebutkan bahwa: faktor Organizational Citizenship Behavior
(OCB) tidak berpengaruh begitu signifikan kepada kinerja organisasi ditolak, dan hipotesis yang diterima (Ha) yang menyatakan bahwa: faktor Organizational Citizenship Behavior (OCB) mempunyai pengaruh yang cukup signifikan.

\section{Uji Koefisien Determinasi}

Uraian model summary statistik, antara lain ialah sebagai berikut:

Model Summarb
\begin{tabular}{|l|c|r|r|r|}
\hline Model & $\mathrm{R}$ & R Square & $\begin{array}{c}\text { Adjusted } \\
\text { R Square }\end{array}$ & $\begin{array}{r}\text { Std. Error of } \\
\text { the Estimate }\end{array}$ \\
\hline 1 & $.791^{\mathrm{a}}$ & .626 & .610 & 4.970 \\
\hline
\end{tabular}
a. Predictors: (Constant), Organizational Citizenship
Behavior
b. Dependent Variable: Kinerja Organisasi

A. Nilai $\mathrm{R}$

$\mathrm{R}=0,791$ atau $\mathrm{R}=79,1 \%$

merupakan koefisien korelasi yang dengan hasil hubungan dari faktor Organizational Citizenship Behavior (OCB) (X) dengan Kinerja Organisasi (Y).

B. Nilai $\mathrm{R}$ Square nilainya 0,626 merupakan $r$ kuadrat dengan hasil jika aspek independen dalam riset ini memiliki peran serta mempengaruhi terhadap aspek dependent sebesar $62,6 \%$ sehingga lebihnya sebesar $37,4 \%$ ialah aspek lainnya yang tidak disebutkan pada riset.

C. Nilai dari adjust $\mathrm{R}$ Square jenis regresinya ini adalah merupakan sebesar 0,601 yang mana menampilkan hasil kalau alterasi ataupun naik atau turunnya Aspek Dependensi (Y) terpengaruh berdasarkan Aspek Independent (X) dengan nilai $60,1 \%$. 


\section{PEMBAHASAN}

\section{Organizational Citizenship}

Behavior (OCB) dianggap sebagai suatu perilaku di tempat kerja yang sesuai dengan penilaian pribadi yang melebihi persyaratan kerja yang seharusnya. Perilaku dalam Organizational Citizenship Behavior yang dimiliki pegawai merupakan syarat perilaku pegawai agar efektif dalam melaksanakan fungsi-fungsinya.

Pembahasan difokuskan pada mengaitkan data dan hasil analisisnya dengan permasalahan atau tujuan penelitian dan konteks teoretis yang lebih luas. Dapat juga pembahasan merupakan jawaban pertanyaan mengapa ditemukan fakta seperti pada data.

Penelitian berdasarkan hasil uji t, variabel Organizational Citizenship Behavior (OCB) berpengaruh positif dan signifikan terhadap kinerja pegawai kantor kecamatan Banjarmasin Utara. Hal ini terbukti berdasarkan hasil pengujian yang telah dilakukan dengan nilai thitung untuk variabel Organizational Citizenship Behavior (OCB) sebesar 6,203 . Dengan menggunakan tabel t, diperoleh angka ttabel sebesar 2,069 sehingga thitung > tabel maka Ho ditolak dan Ha diterima.

\section{KESIMPULAN DAN SARAN}

\section{Kesimpulan}

Jadi kesimpulan dari penelitian yang telah dilaksanakan ini ialah:

\section{Organizational \\ Citizenship} Behavior (OCB) yang memiliki pengaruh positif kepada pegawai dari Kantor
Kecamatan Banjarmasin Utara yang dihasilkan Nilai Koefisien positif sebesar 1,022 pada faktor Organizational Citizenship Behavior (OCB) (X), menunjukan hasil ada terdapat pengaruh searah, yang mana meningkatkan faktor Organizational Citizenship Behavior (OCB) (X) dampaknya pada Kinerja Organisasi (Y) sebesar 100,2\%. Dan juga dari nilai dari uji parsialnya (uji t) adalah thitung $(6,203)>$ ttabel $(2,069)$.

Oleh karena itu, pada penelitian ini hipotesisnya Organizational Citizenship Behavior (OCB), Ha-nya diterima serta Ho ditolak.

Dilihat dari uji koefisien Determinasi Nilai R Square nilainya 0,626 ialah $\mathrm{R}$, pada penelitian ini mempunyai pengaruh yang besar dengan nilai $62,6 \%$ dan lebihnya sebesar $37,4 \%$.

\section{Saran}

Setelah menyelesaikan penelitian ini, maka saran dari penulis khususnya bagi pegawai Kantor Kecamatan Banjarmasin Utara, yaitu:

A. Menciptakan budaya perilaku dan keadaan akan Organizational Citizenship Behavior (OCB) dari para pegawai agar lebih baik lagi.

B. Agar dapat dijadikan sebagai pertimbangan Kantor Kecamatan Banjarmasin Utara, khususnya untuk para pegawai dalam meningkatkan kualitas sumberdaya manusia dalam meningkatkan produktivitas kinerja kantor. 


\section{DAFTAR PUSTAKA}

[1] Andi Hendrawan, H. S. (n.d.). ORGANIZATIONAL

CITIZENSHIP BEHAVIOR (OCB) PADA KARYAWAN PADA KARYAWAN AKADEMI MARITIM NUSANTARA. akademi maritime nusantara, 1-10.

[2] Argita, N. (2018). Pengaruh Organizational Citizenship Behavior (OCB) terhadap Kinerja. Bandung: UIN Sunan Gunung Djati.

[3] Endah Rahayu, Nur Kholifatul Fhitriyah (2018). Pengaruh Organizational Citizenship Behavior (OCB) terhadap Kepuasan Kinerja dan Kinerja Karyawan. Jurnal Teknologi dan Manajemen Agroindustri, 116-123.
[4] Fitria, A. (2013). Pengaruh Komitmen Organisasional dan Organizational Citizenship Behavior (OCB) terhadap Kinerja Pada Pegawai Rumah Sakit Umum Daerah Kraton Pekalongan. 2013: Universitas Muhammadiyah Surakarta.

[5] Nahwati, N. (2019). Pengaruh Organizational Citizenship Behavior (OCB) dan Kompensasi Terhadap Kinerja Karyawan (Studi Pada RS FKU Aisyiyah Boyolali). Semarang: Universitas Wahid Hasyim. 